\title{
Circulating Rotavirus Types and Drug-Resistant Diarrheagenic Escherichia coli Causing Enteric Infection in Under-Five Children in Rural West Bengal, India
}

Kunal Dutta ${ }^{1}$, Barunabha Pal ${ }^{1}$, Rakesh Mandal ${ }^{1}$, Satarupa Mullick ${ }^{2}$, Paulami Mandal ${ }^{2}$, Mukti Kant Nayak $^{2}$, Mamta Chawla-Sarkar ${ }^{2}$ and Chandradipa Ghosh ${ }^{*}$ ${ }^{1}$ Department of Human Physiology with Community Health, Microbiology and Immunology Laboratory, Vidyasagar University, Medinipur-721102, West Bengal, India ${ }^{2}$ Division of Virology, National Institute of Cholera and Enteric Diseases, Kolkata-700010, India

"Corresponding author: Prof. Chandradipa Ghosh, Department of Human Physiology with Community Health, Microbiology and Immunology Laboratory, Vidyasagar University, Medinipur-721102, West Bengal, India, Tel: +913222 276554, extn. 450; E-mail: ch_ghosh@mail.vidyasagar.ac.in

Received Date: October 5, 2018; Accepted Date: October 20, 2018; Published Date: October 29, 2018

Copyright: (c) 2018 Dutta K, et al. This is an open-access article distributed under the terms of the Creative Commons Attribution License, which permits unrestricted use, distribution, and reproduction in any medium, provided the original author and source are credited.

\begin{abstract}
Acute gastroenteritis is an important cause of global morbidity and mortality. In this study, we collected 486 fecal specimens from diarrheal patients during January 2014 to December 2014. We have found G1[P8] as highest prevalent ( $85 \%$ ) genotype of rotavirus followed by G9[P4] (9\%). Furthermore, group A rotavirus $(54.52 \%)$ was found as the primary causative agent of childhood diarrhea and diarrheagenic Escherichia coli $(31.89 \%)$ as the second causative agent. A significant number of rotavirus-bacteria mixed infection was found. The antibiotic susceptibility study reveals the prevalence of multi-drug resistance diarrheagenic Escherichia coli. This study suggests a particular preventive measure for diarrhea during the first the two years of life.
\end{abstract}

Keywords: Acute gastroenteritis; Diarrheagenic Escherichia coli; Rotavirus; G [P] typing

\section{Introduction}

Acute gastroenteritis due to enteropathogens is a leading cause of hospitalization of young children in developed countries and one of the significant causes of mortality in developing countries [1]. In developing countries, each child experience 3.5 to 7.0 diarrheal episodes during first two years of life and 2 to 5 diarrheal episodes up to 5 years of life [2]. The global morbidity and mortality due to single rotavirus infection were estimated about 110 million cases out of which 4 million children die annually [3,4]. In poorest countries, childhood death due to rotavirus gastroenteritis accounts for 85\% [5]. In India, approximately $22 \%$ of the 453,000 deaths among children below five years of age are because of rotavirus gastroenteritis [6] and about 20 to $70 \%$ of hospitalizations are attributable to rotavirus [7]. There are two surface antigens of group A rotavirus called as VP7 (Gtype) and VP4 (P-type) and they have a role in neutralization of host defense mechanism [8]. However, the etiological agents of acute gastroenteritis include a broad range of causative agents that differ significantly with geographical variation [9].

Among other causative agents of acute gastroenteritis, viral agents account for $75 \%$ out of which rotavirus account for $50 \%$ [10], and diarrheagenic Escherichia coli (DEC) is responsible for 30\%-40\% of all diarrheal illness among children $<5$ years of age [11]. The DEC has six major pathotypes including enteroaggregative $E$. coli (EAEC), enteropathogenic E. coli (EPEC), enterohemorrhagic E. coli (EHEC), enterotoxigenic E. coli (ETEC), enteroinvasive E. coli (EIEC), and diffusely adherent $E$. coli (DAEC). The pathotypes of DECs differ in their virulence mechanism and clinical manifestation [12]. They are the primary cause of persistent diarrhea due to their high prevalence both in the hospital, and community setting [13]. In a hospital setting in-patients, diarrhea due to EPEC found in $25.4 \%$ of cases [14].
Worldwide, about 600 million cases of diarrheal illness are attributable to DECs out of which one million children $(<5$ years of age) died annually, and ETEC infections account for about $75 \%$ of it [15]. In a recent report by WHO, EPEC and EAEC are enlisted in top priority pathogens that require immediate vaccine development after rotavirus [16]. Thus in the present time, DECs become a leading cause of the global health burden of diarrheal illness [17]. The financial burden that India has for treating rotavirus infection has been estimated to be 41-72 million US\$ annually [18]. In India about $2.2 \%$ to $5.8 \%$ of the household's annual income incurred directly per diarrheal episodes [19]. It indicate that the economic burden that India has presently to combat diarrheal illness, is also a severe issue in providing and maintaining quality health care services.

In human, $10 \mathrm{G}$-serotypes and $11 \mathrm{P}$-genotypes of rotavirus were identified [20]. Several studies have been suggested severity of rotavirus diarrhea due to different combinations of $G$ and $P$ type. Moreover, a common $\mathrm{G}$ and $\mathrm{P}$ type had never been identified with same or different geographic regions on a different time scale [21]. Thus, it is essential to monitor the prevalent circulating strain to create vaccine development strategies. The present study aimed to determine the predominant genotype of rotavirus and other causative agents of childhood diarrhoea such as Diarrheagenic Escherichia coli (DEC), Vibrio cholerae, Vibrio sp., Shigella sp. and C. jejuni among children under five years of age admitted with diarrheal symptoms in rural areas of West Bengal, India. We also determined the antibiotic susceptibility patterns of enteropathogenic bacteria and prevalence of co-infection among enrolled diarrheal cases.

\section{Materials and Methods}

\section{Study population, study site, and sample collection}

Fecal samples from 486 children $<5$ years of age hospitalized with acute diarrhea were collected from Medinipur Medical College and 
Citation: Dutta K, Pal B, Mandal R, Mullick S, Mandal P, et al. (2018) Circulating Rotavirus Types and Drug-Resistant Diarrheagenic Escherichia coli Causing Enteric Infection in Under-Five Children in Rural West Bengal, India. J Bioengineer \& Biomedical Sci 8: 255. doi: $10.4172 / 2155-9538.1000255$

Page 2 of 8

Hospital (MMC\&H), Medinipur West Bengal, India. The samples were collected for 12 month period from January 2014 to December 2014. The patients were predominantly from rural areas of Paschim Medinipur and Jhargram (Jangamahal area) to take health care services at MMC\&H. Written consents from each patients' guardians were taken before enrollment in this study.

\section{Clinical data collection}

The clinical records from each patient with matched selection criteria were collected with direct supervision of the medical officer. The Vesikari clinical method of diarrheal severity scoring was used for screening the clinical data [21].

\section{Selective isolation and preliminary identification of pathogenic bacteria}

Selective media based method was used for preliminary identification of enteropathogenic bacteria. Eosin methylene blue
(EMB) agar and MacConkey agar were used for identification and isolation of E. coli, Shigella $s p$. Thiosulfate-citrate-bile salts-sucrose (TCBS) agar was used for $V$. cholerae and Vibrio sp. Campylobacter agar was used for Campylobacter jejuni. All selective media and LuriaBertani (LB) were purchased from HiMedia Laboratory, India.

\section{Nucleic acid extraction and polymerase chain reaction}

Extraction of genomic DNA from each isolate was carried out by genomic DNA kit (QIAGEN, India). The extracted genomic DNA from each strain was then quantified at 260/280 nm using spectrophotometer (UV-1800, Shimadzu, Japan) and used as template DNA $\left(1 \mu \mathrm{g} \mathrm{ml}^{-1}\right.$ as final conc.) in the PCR. The PCR was developed by using 2X PCR TaqMixture (HiMedia, India). The final reaction volume was $25 \mu \mathrm{l}$. The primer sequences and PCR program that was used is described in Table 1. The PCR products were checked in $1.0 \mathrm{~g} \%(\mathrm{w} / \mathrm{v})$ agarose gel electrophoresis and photographed using Gel Doc XR (Gel Doc, Bio-Rad, USA).

\begin{tabular}{|c|c|c|c|c|}
\hline Enteropathogenic Bacteria & $\begin{array}{l}\text { Primer } \\
\text { name }\end{array}$ & Primer Sequences 5' to $3^{\prime}$ & Product size & References \\
\hline \multirow[b]{2}{*}{$\operatorname{EPEC}(b f p A)$} & $\mathrm{F}$ & AATGGTGCTTGCGCTTGCTGC & \multirow[b]{2}{*}{326 bp } & \multirow[b]{2}{*}{ Gómez-Duarte et al. [22] } \\
\hline & $\mathrm{R}$ & GCCGCTTTATCCAACCTGGTA & & \\
\hline \multirow[b]{2}{*}{ EAEC (aggR) } & $\mathrm{F}$ & GTATACACAAAAGAAGGAAGC & \multirow[b]{2}{*}{$254 \mathrm{bp}$} & \multirow[b]{2}{*}{ Gómez-Duarte et al. [22] } \\
\hline & $\mathrm{R}$ & ACAGAATCGTCAGCATCAGC & & \\
\hline \multirow[b]{2}{*}{ EIEC (ipaH) } & $\mathrm{F}$ & CTCGGCACGTTTTAATAGTCTGG & \multirow[b]{2}{*}{$933 \mathrm{bp}$} & \multirow[b]{2}{*}{ Gómez-Duarte et al. [22] } \\
\hline & $\mathrm{R}$ & GTGGAGAGCTGAAGTTTCTCTGC & & \\
\hline \multirow[b]{2}{*}{$\operatorname{ETEC}(S T)$} & $\mathrm{F}$ & GCTAAACCAGTAGAG(C)TCTTCAAAA & \multirow[b]{2}{*}{$147 \mathrm{bp}$} & \multirow[b]{2}{*}{ Gómez-Duarte et al. [22] } \\
\hline & $\mathrm{R}$ & CCCGGTACAG(A)GCAGGATTACAACA & & \\
\hline \multirow[b]{2}{*}{ EHEC (eaeA) } & $\mathrm{F}$ & GTGGCGAATACTGGCGAGACT & \multirow[b]{2}{*}{$890 \mathrm{bp}$} & \multirow[b]{2}{*}{ Fagan et al. [23] } \\
\hline & $\mathrm{R}$ & CCССАTTCTTTTTCACCGTCG & & \\
\hline \multirow[b]{2}{*}{ Vibrio spp.(16sRNA) } & $\mathrm{F}$ & CAATGGGCGCAAGCCTGATG & \multirow[b]{2}{*}{$889 \mathrm{bp}$} & \multirow[b]{2}{*}{ This study } \\
\hline & $\mathrm{R}$ & GCTGCCCTCTGTATACGCCA & & \\
\hline \multirow{2}{*}{$\begin{array}{l}\text { Vibrio cholerae } \\
\text { (16SrRNA) }\end{array}$} & $\mathrm{F}$ & AGCAAAGCAGGGGACCTTCG & \multirow[b]{2}{*}{$870 \mathrm{bp}$} & \multirow[b]{2}{*}{ This study } \\
\hline & $\mathrm{R}$ & CAGCCATGCAGCACCTGTCT & & \\
\hline \multirow{2}{*}{$\begin{array}{l}\text { Shigella sp } \\
(16 S r R N A)\end{array}$} & $\mathrm{F}$ & TTGCTGCTTCGCTGACGAGT & \multirow[b]{2}{*}{472 bp } & \multirow[b]{2}{*}{ This study } \\
\hline & $\mathrm{R}$ & TTAACGCTTGCACCCTCCGT & & \\
\hline \multirow[b]{2}{*}{ Campylobactor jejuni (16SrRNA) } & $\mathrm{F}$ & ATCACTGGGCGTAAAGGGCG & \multirow[b]{2}{*}{$559 \mathrm{bp}$} & \multirow[b]{2}{*}{ This study } \\
\hline & $\mathrm{R}$ & AATACGTGGGTTGCGCTCGT & & \\
\hline
\end{tabular}

Table 1: Primer sequences and PCR amplicon size.

\section{Detection of rotavirus antigen by enzyme immunoassays (EIA)}

The detection of rotavirus antigen was performed by using Premier ${ }^{\mathrm{rm}}$ Rotaclone kit (Fisher Scientific). Viral suspension (VS) was prepared by adding $1 \mathrm{ml}$ of sample diluent (provided in the kit) to $1.5 \mathrm{ml}$ microfuge tube to prepare a $10 \%$ suspension or dilution of the fecal specimen by the addition of approximately $0.1 \mathrm{~g}$ of solid feces (small pea-sized portion) or approximately $100 \mu \mathrm{l}$ of liquid feces. After thoroughly mixing the suspensions were centrifuged at $10,000 \mathrm{rpm}$ for 10 minutes at $4^{\circ} \mathrm{C}$. The supernatant was collected carefully in a new tube and was used for enzyme immunoassay (EIA). Rest of the protocol was followed as described by the original kit manufacturer. 
Citation: Dutta K, Pal B, Mandal R, Mullick S, Mandal P, et al. (2018) Circulating Rotavirus Types and Drug-Resistant Diarrheagenic Escherichia coli Causing Enteric Infection in Under-Five Children in Rural West Bengal, India. J Bioengineer \& Biomedical Sci 8: 255. doi: $10.4172 / 2155-9538.1000255$

Page 3 of 8

\section{Extraction of viral dsRNA}

Viral dsRNA was extracted using QIAamp ${ }^{\bullet}$ Viral RNA Kit (Qiagen, USA). A stool suspension in sterile Dulbecco's phosphate-buffered saline by adding $0.3 \mathrm{~g}$ of solid faeces or approximately $300 \mu \mathrm{l}$ of liquid faeces in $700 \mu \mathrm{l}$ of PBS. After thoroughly vortexing for $1 \mathrm{~min}$ centrifugation was performed at $10000 \mathrm{rpm}$ for $10 \mathrm{~min}$ at $4^{\circ} \mathrm{C}$. The clear supernatant was transferred into the sterile $1.5 \mathrm{ml}$ micro centrifuge tube and stored at $4^{\circ} \mathrm{C}$ until use. Rest of the protocol was followed as described by the original kit manufacturer.

\section{Reverse transcriptase (RT) PCR}

Total RNA was extracted using the PureLink ${ }^{\text {tw }}$ RNA Mini Kit (Invitrogen, Carlsbad, CA) and quantified using a UV-Vis spectrophotometers (Mecasys Co. LTD, Korea). Total RNA was then converted to cDNA by using Verso cDNA synthesis kit (Thermo Scientific, USA). The standard reaction contained 1x Power SYBR Green PCR master mix (Applied Biosystems), respective primer pairs and CDNA as the template strand. The temperature program for 40 cycles were set to denaturation at $94^{\circ} \mathrm{C}$ for $1 \mathrm{~min}$, annealing at $55^{\circ} \mathrm{C}$ for $45 \mathrm{sec}$. The reaction was conducted in StepOnePlus Real-Time PCR System (Applied Biosystems). The samples were analyzed in triplicate and the recA was used as endogenous control for normalization.

\section{G type and P type PCR (multiplex semi-nested)}

The multiplex semi-nested technique was implemented to determine G-P type of the rotavirus strains. The synthesized cDNA was used as the template to determine G-P type of every 3rd rotavirus positive sample. The temperature program and primer sets used are listed in Table 1 . The PCR products were then analyzed in $1.2 \%$ agarose gel in 1x TBE buffer and photographed using Gel doc (BioRad, USA).

\section{Antimicrobial susceptibility test (AST)}

AST of clinical isolates was determined using the Kirby-Bauer disk diffusion method and interpreted by CLSI guidelines [24]. The isolates were tested against the following antibiotics, Amikacin (AK), Ampicillin (AMP), Amoxycillin (AMC), Ceftriaxone (CTR), Cefepime (CPM), Doxycycline $\mathrm{HCl}$ (DO), Norfloxacin (NX), Tobramycin
(TOB), Gentamicin (GEN), Nitrofurantoin (NIT), Chloramphenicol (C). All antibiotic disks were purchased from HiMedia Laboratory, India.

\section{Statistical analysis}

Differences in proportions were assessed by a chi-square test and Fisher's exact test whichever applicable. The analysis of variance (ANOVA) was performed for quantitative variables. $\mathrm{P}$ values $<0.05$ were considered statistically significant. All statistical test was performed using Graphpad Prism ${ }^{\circledR} 6.01$ (Santiago, USA) software packages.

\section{Results}

\section{Clinical severity of studied population}

The clinical record analysis according to Vesikari clinical severity score [21], revealed that out of 453 children, 355 children were admitted with moderate diarrheal symptoms and 131 children were admitted with severe diarrheal symptoms, and the rotavirus antigen was detected positive in 197 and 68 fecal samples respectively (Table 2). The clinical manifestations and sign of dehydration, the immediate treatment recommended by the medical officer are summarized in Table 3.

\begin{tabular}{|l|l|l|l|l|}
\hline \multirow{2}{*}{} & \multicolumn{4}{|l|}{ Total severity score } \\
\cline { 2 - 5 } & $\begin{array}{l}\text { Mild } \\
\text { Disease }\end{array}$ & Moderate & Severe & $\begin{array}{l}\text { Very } \\
\text { severe }\end{array}$ \\
\cline { 2 - 5 } Rotavirus detection & $\mathbf{( 0 - 5 )}$ & $\mathbf{( 6 - 1 0 )}$ & $\mathbf{( 1 1 - 1 5 )}$ & $\mathbf{( 1 6 - 2 0 )}$ \\
\hline Total no. patient $(n=486)$ & 0 & 355 & 131 & 0 \\
\hline Positive $(n=265)$ & 0 & 197 & 68 & 0 \\
\hline Negative $(n=221)$ & 0 & 158 & 63 & 0 \\
\hline
\end{tabular}

Table 2: Difference and relationship between Vesikari clinical severity score and prevalence of rotavirus at MMC\&H.

\begin{tabular}{|c|c|c|c|c|c|c|c|c|c|c|}
\hline \multirow[b]{2}{*}{ Rotavirus detection } & \multicolumn{5}{|c|}{ Stool appearance* } & \multicolumn{5}{|c|}{ Sign of dehydration on admission } \\
\hline & Watery & Semisolid & Bloody & Mucous & $\begin{array}{l}\text { Rice } \\
\text { water }\end{array}$ & Lethargy & Restless & $\begin{array}{l}\text { Feeding } \\
\text { well }\end{array}$ & $\begin{array}{l}\text { Eyes } \\
\text { sunken }\end{array}$ & Skin Pitch \\
\hline Total no. of patients & 191 & 97 & 8 & 67 & 49 & 486 & 486 & 486 & 7 & 0 \\
\hline Positive (n=265) & 147 & 50 & 3 & 41 & 24 & 486 & 486 & 486 & 3 & 0 \\
\hline Negative $(n=221)$ & 84 & 43 & 24 & 38 & 32 & 0 & 0 & 0 & 476 & 0 \\
\hline
\end{tabular}

Table 3: Clinical manifestation, sign of dehydration, immediate treatment in children admitted with acute diarrhea at MMC\&H.

\section{Molecular identification of rotavirus}

The GP typing results shows that in this region G1P[8] (85\%), most prevalent strain followed by G9P[4] (5\%), G2P[4] (3\%), G9P[8] and G2[6] were detected only $1 \%$ among the rotavirus positive strains (Figure 1). In our study, G9P[6] was not detected. 
Citation: Dutta K, Pal B, Mandal R, Mullick S, Mandal P, et al. (2018) Circulating Rotavirus Types and Drug-Resistant Diarrheagenic Escherichia coli Causing Enteric Infection in Under-Five Children in Rural West Bengal, India. J Bioengineer \& Biomedical Sci 8: 255. doi:

Page 4 of 8

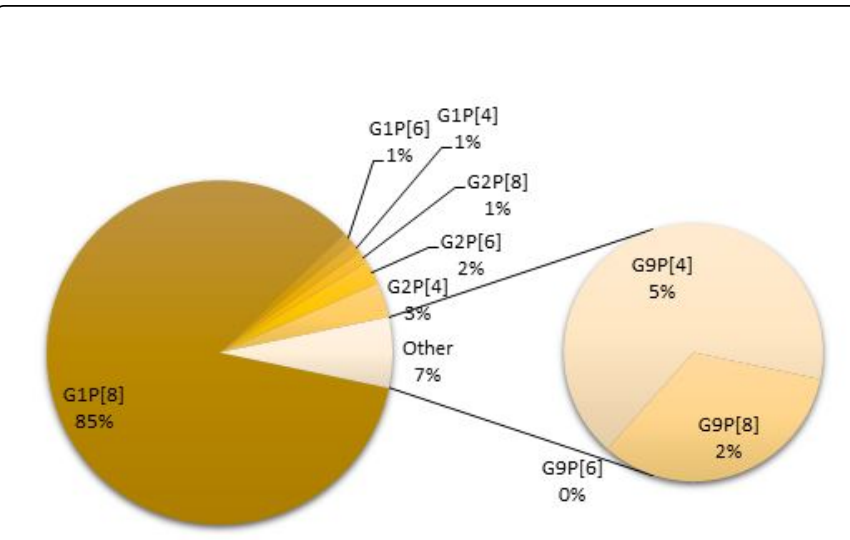

\section{Prevalence of enteropathogenic bacteria}

The selective media based isolation followed by multiplex polymerase chain reactions show that Enteropathogenic Escherichia coli (EPEC) was the prevalent group. Eighty-one isolates (19.66\%) belonged to this group. The second prevalent group detected was Enteroaggregative Escherichia coli (EAEC), and 44 isolates (10.67\%) belonged to this group. The third prevalent pathogen was Vibrio cholerae and 34 isolates (8.25\%) were identified by PCR (Table 4). Enterotoxigenic Escherichia coli (ETEC), Shigella sp. and Vibrio sp. were next to $V$. cholerae and 21,27, 14 strains were identified, respectively. A very negligible number of Campylobactor jejuni $(\mathrm{n}=6)$, Enterohemorrhagic Escherichia coli (EHEC) (n=3), Enteroinvasive Escherichia coli (EIEC) $(\mathrm{n}=2)$ were detected in this study. Three fecal specimens did not belong to any of the target enteropathogenic bacteria group (Table 4).

Figure 1: G-P Type detected during the surveillance at MMC\&H.

\begin{tabular}{|c|c|c|c|c|c|}
\hline \multirow[b]{4}{*}{ Rotavirus detection } & \multicolumn{2}{|c|}{ Total no. of patient admitted } & Total no. Sample collected & $\begin{array}{l}\text { Total no. of Rotavirus positive } \\
\text { sample }\end{array}$ & Rotavirus Positive (\%) \\
\hline & \multicolumn{2}{|l|}{759} & 486 & 265 & 54.52 \\
\hline & \multicolumn{5}{|c|}{ Age groups (month)* } \\
\hline & $0-6$ & $06-12$ & $12-24$ & $24-36$ & $36-60$ \\
\hline Positive $(n=265)$ & 21 & 123 & 107 & 17 & 12 \\
\hline $\operatorname{EPEC}(n=81)$ & 40 & 18 & 13 & 7 & 3 \\
\hline $\operatorname{EAEC}(n=44)$ & 6 & 25 & 11 & 1 & 0 \\
\hline $\operatorname{EIEC~}(n=2)$ & 0 & 0 & 0 & 1 & 1 \\
\hline $\operatorname{ETEC}(n=21)$ & 1 & 2 & 15 & 1 & 2 \\
\hline $\operatorname{EHEC}(n=3)$ & 0 & 0 & 0 & 1 & 2 \\
\hline VC $(n=34)$ & 6 & 21 & 5 & 2 & 3 \\
\hline Vsp. $(n=14)$ & 0 & 9 & 4 & 1 & 0 \\
\hline Ssp. $(n=27)$ & 0 & 2 & 19 & 2 & 4 \\
\hline CJ $(n=6)$ & 0 & 0 & 0 & 2 & 4 \\
\hline Unidentified $(n=3)$ & 0 & 0 & 26 & 3 & 4 \\
\hline
\end{tabular}

Table 4: Prevalence of rotavirus and diarrheagenic E. coli (DEC) among children $<5$ years of age admitted with diarrheal symptoms at MMC\&H.

\section{Co-infection with multiple enteropathogens and rotavirus}

One hundred and fifty-five (34.21\%) cases of co-infections were detected among 453 fecal specimens (Table 5). The co-infection were prevalent between rotavirus and enteropathogenic bacteria (83.22\%). EPEC, EAEC, EIEC, ETEC, Vibrio cholerae, Vibrio sp., Shigella sp. and Campylobactor jejuni were detected respectively, $47.28 \%, 17.05 \%$, $0.77 \%, 5.42 \%, 14.72 \%, 2.32 \%, 9.30 \%$, and $3.10 \%$ with rotavirus infection. Bacteria-bacteria (DEC-DEC) co-infection were found positive in very few cases (16.77\%). Whereas, Diarrheagenic
Escherichia coli (DEC) and Vibrio cholerae co-infection were found in 11 fecal specimens.

\begin{tabular}{|l|l|}
\hline Co-infections types & No. of case \\
\hline Rotavirus co-infection & 61 \\
\hline Rotavirus+EPEC & 22 \\
\hline Rotavirus+EAEC & \\
\hline
\end{tabular}


Citation: Dutta K, Pal B, Mandal R, Mullick S, Mandal P, et al. (2018) Circulating Rotavirus Types and Drug-Resistant Diarrheagenic Escherichia coli Causing Enteric Infection in Under-Five Children in Rural West Bengal, India. J Bioengineer \& Biomedical Sci 8: 255. doi: $10.4172 / 2155-9538.1000255$

Page 5 of 8

\begin{tabular}{|l|l|}
\hline Rotavirus+EIEC & 1 \\
\hline Rotavirus+ETEC & 7 \\
\hline Rotavirus+EHEC & 0 \\
\hline Rotavirus+VC & 19 \\
\hline Rotavirus+Vsp & 3 \\
\hline Rotavirus+Ssp & 12 \\
\hline Rotavirus+CJ & 4 \\
\hline DEC-DEC co-infection & 7 \\
\hline EPEC+EAEC & 0 \\
\hline EPEC+EIEC & 2 \\
\hline EPEC+ETEC & 0 \\
\hline EPEC+EHEC & 0 \\
\hline EIEC+ETEC & 0 \\
\hline EIEC+EHEC & 1 \\
\hline ETEC+EHEC & 11 \\
\hline DEC - other bacteria co-infection & 0 \\
\hline DEC+VC & 1 \\
\hline DEC+VC+Ssp. & \\
\hline VC+SP & \\
\hline DEC+SP & 1 \\
\hline
\end{tabular}

Table 5: Prevalence of co-infections among children $<5$ years of age admitted with diarrheal symptoms in MMC\&H.

\section{Antibiotic susceptibility test (AST)}

The AST was conducted to identify antibiotic susceptibility patterns among enteropathogenic bacterial isolates (Figure 2). The data obtained from AST revealed that CTR, CTX, AMP, and NX were highly resistance among all studied enteropathogens and they revealed 82.089\% (Vibrio cholerae), 80.12\% (EPEC), 71.64\% (Vibrio sp.), and $55.26 \%$ (EAEC) respectively. AK was found highest sensitive for EPEC (97.51\%) among all tested enteropathogens.

\section{Prevalence of rotavirus and seasonal variation}

Two hundred and eight fecal specimens were found rotavirus positive, which is $61.81 \%$ out of $453 \mathrm{fecal}$ samples. The high susceptible age group was found to be 6-12 month $(\mathrm{P}<0.05), 43.92 \%$ samples belonged to this group (Figure 3 ). The second susceptible age group was found to be $12-24$ month $(\mathrm{P}<0.05), 38.21 \%$ samples belonged to this group (Table 4). The enrolled case data analysis revealed that rotavirus is prevalent in the winter season (December-February) and during onset of summer (March-April) was highest (Figure 4). The same phenomenon was also observed for prevalent $G$ and $P$ types of rotavirus (Figures 5 and 6). In March 2014 significantly $(\mathrm{P}<0.0001)$ high prevalence $(25.71 \%)$ of rotavirus was detected and in December 2014, February 2014 and January 2014 the prevalence rate of rotavirus was $18.92 \%, 14.28 \%$, and $10.35 \%$, respectively.

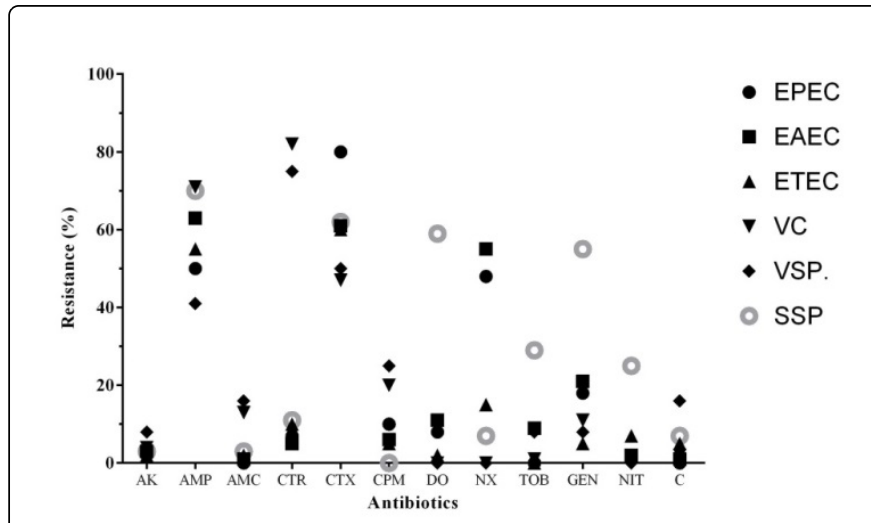

Figure 2: Antibiotic susceptibility test among different enteropathogenic bacteria isolated from fecal specimen of children (age $<5$ years) admitted with diarrheal symptoms at MMC\&H. Amikacin (AK), Ampicillin (AMP), Amoxycillin (AMC), Ceftriaxone (CTR), Cefepime (CPM), Doxycycline $\mathrm{HCl}(\mathrm{DO})$, Norfloxacin (NX), Tobramycin (TOB), Gentamicin (GEN), Nitrofurantoin (NIT), Chloramphenicol (C). Enteropathogenic E. coli (EPEC), Enteroaggregative E. coli (EAEC), Enterotoxigenic E. coli (ETEC), Vibrio cholerae (VC), Vibrio sp.(VSP), Shigella sp. (SSP).

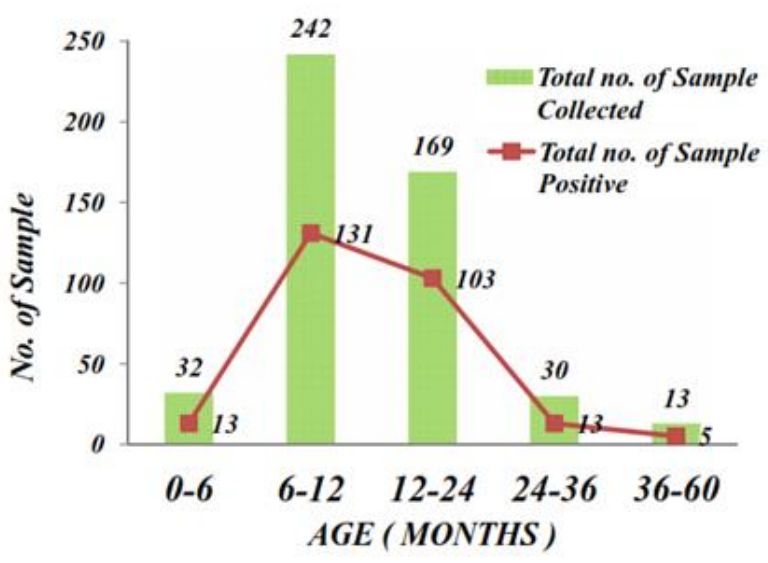

Figure 3: Age-wise distribution of rotavirus positive at MMC\&H. 
Citation: Dutta K, Pal B, Mandal R, Mullick S, Mandal P, et al. (2018) Circulating Rotavirus Types and Drug-Resistant Diarrheagenic Escherichia coli Causing Enteric Infection in Under-Five Children in Rural West Bengal, India. J Bioengineer \& Biomedical Sci 8: 255. doi: $10.4172 / 2155-9538.1000255$

Page 6 of 8

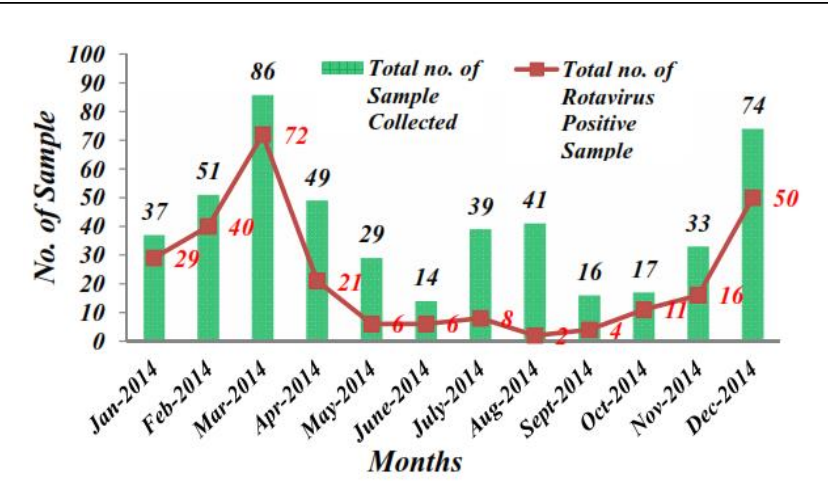

Figure 4: Month-wise distribution of Sample Collection and Positivity for Rotavirus at MMC\&H. The gray bar and numerical value on top indicates total number of sample collection in that particular month. The black line and adjacent numerical values indicated number of rotavirus positive cases.

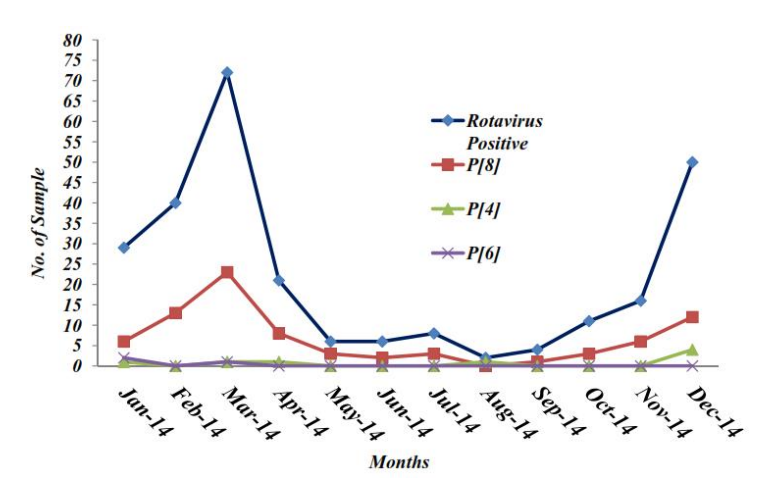

Figure 5: Month-wise detection of P-types of circulating rotavirus at MMC\&H.

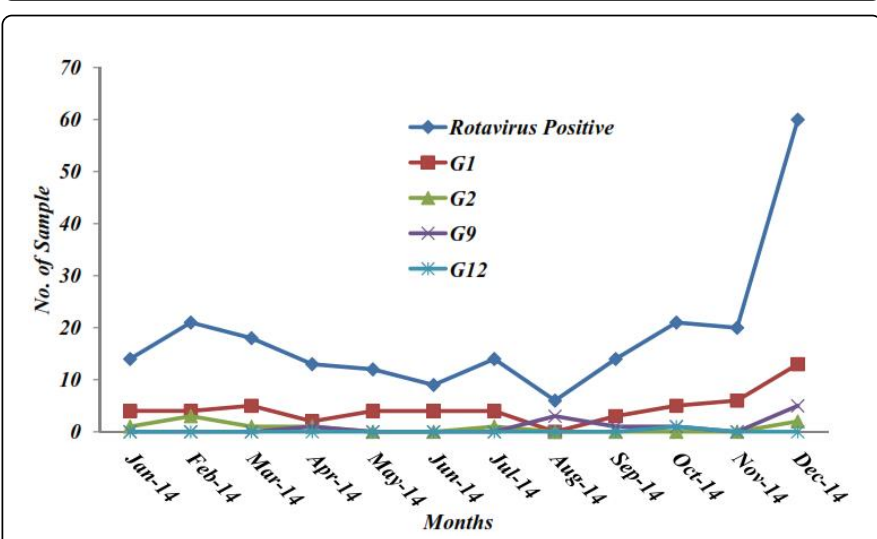

Figure 6: Month-wise detection of G-types of circulating rotavirus at MMC\&H.

\section{Discussion}

In this study, we investigated the burden of rotavirus and other enteropathogens among children $(<5$ years of age) admitted with diarrheal symptoms. We observed 40.53\% (197/486) children were admitted with severe diarrheal symptoms (AGE with vomiting or AGE with some dehydration) out of which $16.99 \%$ children were $<12$ years of age. This severity may be primarily due to lack of proper parental care, poor maternal diet, malnutrition, lack of health education, poor socio-economic status and irregular breast-feeding [25]. We have observed that children less than 24 months of age were susceptible to rotaviral diarrhea, comprising $48.14 \%$ of all diarrheal cases and $88.30 \%$ of all positive rotavirus cases $(\mathrm{P}<0.05)$. However, this prevalence rate was lower in other countries [26]. This difference is due to muchinfluencing factors including geo-demographic variations, the measure was taken during sample collections, and most importantly socioeconomic status and mother-child nutrition [27]. We have observed that group A rotavirus was prevalent $(54.52 \%, 265 / 486)$ among all diarrheal cases. Furthermore, enteropathogenic bacteria was prevalent $(48.35 \%)$ in children $(<5$ years) with diarrheal symptoms. Thus, this study confirming group A rotavirus as a main etiological agent in pediatric diarrhea [28]. However, the prevalence of enteropathogenic bacteria was low in the previous study [29]. Several lines of documents have suggested that the prevalence of diarrhea is strongly associated with sanitation [30]. The isolated bacteria are indicators of fecal contamination, indicating low hygiene in the intake of foods $[31,32]$. Moreover, young children those were taking health care services at $\mathrm{MMC} \& \mathrm{H}$, primarily belonged to the low socioeconomic group and had a poor living standard, which is the main reason for this high prevalence of diarrheagenic bacteria [33]. In our study, G1P[8] (85.0\%) was most prevalent genotype followed by G9[P4] (5\%), G2[P4] (3\%), G2[P6] (2\%), others variants were detected only $1 \%$ among the rotavirus positive cases. Several other studies also suggested that G1P[8] genotype to be predominant genotype of group A rotavirus worldwide [9]. Taken together, our study suggests the region-specific emergence of rotavirus strains and it is important to develop vaccine strategies. The spectrum of enteropathogenic bacteria detected during this study, shows that EPEC, EAEC, EIEC, ETEC, EHEC, Vibrio cholerae, Vibrio sp., Shigella sp., and C. jejuni were $17.88 \%, 9.71 \%, 0.44 \%, 4.63 \%, 0.66 \%, 7.50 \%, 3.09 \%, 5.96 \%$ and $1.32 \%$, respectively. In $7.06 \%$ cases, target enteropathogenic bacteria were not found. We have also found EPEC to be prevalent of $49.38 \%(40 / 81)$ among children $<6$ months of age and EAEC was prevalent at $59.09 \%$ (26/44) among children 6-12 months of age. Similar results were obtained in the previous study [34]. Thus, indicating a marked age group for DECs infection among children $(<5$ years) in this area. The demonstrating role of different pathotypes of diarrheagenic $E$. coli in diarrheal diseases had also been reported elsewhere [12]. It may be due to decline protection by maternal antibodies, changing food habits [35]. The younger children are usually less infected by DECs pathotypes due to their natural acquired immunity [36]. The DECs detection rates have been reported to correlate with the seasons [37]. We observed that the seasonal spectrum of etiological agents causing diarrhea among children ( $<5$ years) is similar to other study [37]. In our study, we have found that during the winter season (Nov 2014February 2014) and in early summer (March 2014-April 2014) occurrence of rotavirus infection was $52.87 \%$ and $33.45 \%$ respectively. However, early summer occurrence rate was high in the previous study [38]. In the summer EPEC, EAEC, ETEC, Shigella sp. and C. jejuni were prevalent by $77.77 \%, 86.36 \%, 90.47 \%$ respectively and Shigella sp. and $C$. jejuni both were prevalent by $100 \%$. Whereas, Vibrio cholerae and Vibrio sp. prevalent by $88.23 \%$ and $85.71 \%$ in the rainy season $[11,39]$. A higher prevalence of diarrheagenic E. coli was detected during summer whereas, Vibrio cholerae and Vibrio sp. were prevalent during the rainy season $(\mathrm{p}<0.05)$. The prevalence of Vibrio sp. in rainy 
Citation: Dutta K, Pal B, Mandal R, Mullick S, Mandal P, et al. (2018) Circulating Rotavirus Types and Drug-Resistant Diarrheagenic Escherichia coli Causing Enteric Infection in Under-Five Children in Rural West Bengal, India. J Bioengineer \& Biomedical Sci 8: 255. doi: $10.4172 / 2155-9538.1000255$

Page 7 of 8

seasons may be due the quality of the water sources being compromised with surface runoff [18]. In this study, we observed $31.89 \%(155 / 486)$ of children were infected with more than one causative pathogen of diarrhea. This higher prevalence of mixed infections may be due to one single causative agent that is facilitating other pathogens to challenge host immune system and vice versa. The rotavirus and diarrheagenic Escherichia coli (DEC) co-infection was 26.54\% (129/486) prevalent out of which EPEC + EAEC alone was $21.76 \%$ (all positive rotavirus cases) and $13.46 \%$ (all diarrheal cases). EAEC+ETEC and Vibrio cholerae were prevalent by $7.85 \%$ and $4.85 \%$, respectively (all diarrheal cases). Co-infections among different DECs pathotypes were not detected significantly $(p>0.05)$. Only seven cases (1.54\%) EPEC-EAEC and one case $(0.24 \%)$ of ETEC-EHEC coinfection were detected in this study. However, eleven cases $(2.42 \%)$ EPEC-Vibrio cholerae and four cases $(0.88 \%)$ of Vibrio cholerae and Vibrio sp. and one instance of EAEC and Shigela sp. (0.22\%) were detected in this study. These findings were found similar with a prior report [40-44]. We observed that the antimicrobial therapy had not been initiated before admission in most of the cases. We have observed highest resistance for CTX (80.24\%) in EPEC, $(72.72 \%)$ in EAEC. VC was found with highest resistance in CTR $(82.35 \%)$ and $73.52 \%$ for AMP, which is the most commonly prescribed antimicrobial treatment for the children admitted to health care center. However, the resistance rates to the newer generation antimicrobials (Amikacin) as detected in our study were still low. Enteropathogens were found sensitive for Amikacin and Chloramphenicol ranging from 83.33 to $100 \%$. However, the use of Chloramphenicol is not recommended in younger children [45-47].

\section{Conclusion}

Vaccination against particular disease directly reduces annual health care cost and ensures better public healthcare services of any nation. However, it is quite tough job for scientist to formulate a common vaccine against disease that is caused by diverse variety of serotypes. In India childhood diarrhoea due to rotavirus and diarrheagenic E. coli cause huge loss of per-capita income. The reduction of this great loss of nation's economy can only be possible by the formulation of an effective cocktail vaccine for childhood diarrhoea, specifically against rotavirus. Presently no such vaccine available in the market for childhood diarrhoea and the vaccine available for rotavirus is with poor efficacy rate due to diversity of circulating serotypes.

Our study has identified the emergence of G1P[8] rotavirus strain and EPEC in rural areas of West Bengal in particular. It is an important clue for the development of an effective cocktail vaccine or regionspecific rota-vaccine. Our study also suggests particularly 6-12 year age group of children are vulnerable to DECs and rotavirus infections therefore, we recommend specific preventive measures to control DECs, specifically in the summer season and during winter seasons rotavirus prevention of rotaviral infection and oversight should be emphasized.

\section{Acknowledgement}

Indian Council of Medical Research (ICMR), Govt. of India (Project No. 5/8-1 (189)/TF/2011-12 ECD Dated 24.01.2013/05.02.13) is sincerely acknowledged by authors.

\section{Ethical Consideration}

The ethical committee at Vidyasagar University approve the study.

\section{References}

1. Parkin PC, Macarthur C, Khambalia A, Goldman RD, Friedman JN (2010) Clinical and laboratory assessment of dehydration severity in children with acute gastroenteritis. Clin Pediatr 49: 235-239.

2. Zheng S, Yu F, Chen X, Cui D, Cheng Y, et al. (2016) Enteropathogens in children less than 5 years of age with acute diarrhea: a 5-year surveillance study in the southeast coast of China. BMC Infect Dis 16: 434.

3. Abebe A, Teka T, Kassa T, Seheri M, Beyene B, et al. (2014) Hospitalbased surveillance for rotavirus gastroenteritis in children younger than 5 years of age in Ethiopia: 2007-2012. Pediatr Infect Dis J 33: S28-S33.

4. Alkoshi S, Maimaiti N, Dahlui M (2014) Cost-effectiveness analysis of rotavirus vaccination among Libyan children using a simple economic model. Libyan J Med 9: 26236.

5. Parashar UD, Hummelman EG, Bresee JS, Miller MA, Glass RI (2003) Global illness and deaths caused by rotavirus disease in children. Emerg Infect Dis 9: 565.

6. Kang G, Desai R, Arora R, Chitamabar S, Naik TN, et al. (2013) Diversity of circulating rotavirus strains in children hospitalized with diarrhea in India, 2005-2009. Vaccine 31: 2879-2883.

7. Mukherjee A, Chawla-Sarkar M (2011) Rotavirus infection: a perspective on epidemiology, genomic diversity and vaccine strategies. Indian J Virol 22: 11-23.

8. Unicomb LE, Podder G, Gentsch JR, Woods PA, Hasan KZ, et al. (1999) Evidence of high-frequency genomic reassortment of group A rotavirus strains in Bangladesh: emergence of type G9 in 1995. J Clin Microbiol 37: 1885-1891.

9. Durmaz R, Kalaycioglu AT, Acar S, Bakkaloglu Z, Karagoz A, et al. (2014) Prevalence of rotavirus genotypes in children younger than 5 years of age before the introduction of a universal rotavirus vaccination program: report of rotavirus surveillance in Turkey. PLoS One 9: e113674.

10. Bizuneh T, Abebe A, Lema E (2017) Rotavirus infection in under-five children in Jimma Hospital, Southwest Ethiopia. Ethiop J Health Dev 18: 19-24.

11. Patzi-Vargas S, Zaidi MB, Perez-Martinez I, León-Cen M, Michel-Ayala A, et al. (2015) Diarrheagenic Escherichia coli carrying supplementary virulence genes are an important cause of moderate to severe diarrhoeal disease in Mexico. PLoS Negl Trop Dis 9: e0003510.

12. Gomes TA, Elias WP, Scaletsky IC, Guth BE, Rodrigues JF, et al. (2016) Diarrheagenic Escherichia coli. braz j microbial 47: 3-30.

13. Pawlowski SW, Warren CA, Guerrant R (2009) Diagnosis and treatment of acute or persistent diarrhea. Gastroenterology 136: 1874-1886.

14. Ochoa TJ, Contreras CA (2011) Enteropathogenic E. coli (EPEC) infection in children. Curr Opin Infect Dis 24: 478.

15. Fleckenstein J, Sheikh A, Qadri F (2014) Novel antigens for enterotoxigenic Escherichia coli vaccines. Expert Rev Vaccines 13: 631-639.

16. Lanata CF, Fischer-Walker CL, Olascoaga AC, Torres CX, Aryee MJ, et al. (2013) Global causes of diarrheal disease mortality in children $<5$ years of age: a systematic review. PLoS One 8: e72788.

17. Tate JE, Chitambar S, Esposito DH, Sarkar R, Gladstone B, et al. (2009) Disease and economic burden of rotavirus diarrhoea in India. Vaccine 27: F18-F24.

18. Mendelsohn AS, Asirvatham JR, Mkaya Mwamburi D, Sowmynarayanan T, Malik V, et al. (2008) Estimates of the economic burden of rotavirusassociated and all-cause diarrhoea in Vellore, India. Trop Med Int Health 13: 934-942.

19. Ramachandran M, Das BK, Vij A, Kumar R, Bhambal S, et al. (1996) Unusual diversity of human rotavirus $\mathrm{G}$ and $\mathrm{P}$ genotypes in India. J Clin Microbiol 34: 436-439.

20. Zimber U, Adldinger HK, Lenoir GM, Vuillaume M, Knebel-Doeberitz MV, et al. (1986) Geographical prevalence of two types of Epstein-Barr virus. Virology 154: 56-66. 
Citation: Dutta K, Pal B, Mandal R, Mullick S, Mandal P, et al. (2018) Circulating Rotavirus Types and Drug-Resistant Diarrheagenic Escherichia coli Causing Enteric Infection in Under-Five Children in Rural West Bengal, India. J Bioengineer \& Biomedical Sci 8: 255. doi: $10.4172 / 2155-9538.1000255$

Page 8 of 8

21. Ruuska T, Vesikari T (1991) A prospective study of acute diarrhoea in Finnish children from birth to 2 1/2 years of age. Acta Paediatr Scand 80: 500-507.

22. Gómez-Duarte OG, Arzuza O, Urbina D, Bai J, Guerra J, et al. (2010) Detection of Escherichia coli enteropathogens by multiplex polymerase chain reaction from children's diarrheal stools in two CaribbeanColombian cities. Foodborne Pathog Dis 7: 199-206.

23. Fagan PK, Hornitzky MA, Bettelheim KA, Djordjevic SP (1999) Detection of Shiga-like toxin (stx1 andstx2), intimin (eaeA), and enterohemorrhagic Escherichia coli (EHEC) hemolysin (EHEC hlyA) genes in animal feces by multiplex PCR. Appl Environ Microbiol 65: 868-872.

24. Wayne P (2015) CLSI. Performance Standards for Antimicrobial Susceptibility Testing; Twenty-Fifth Informational Supplement. CLSI Document M100-S25, Clinical and Laboratory Standards Institute.

25. Chisti MJ, Salam MA, Smith JH, Ahmed T, Ashraf H, et al. (2011) Impact of lack of breast feeding during neonatal age on the development of clinical signs of pneumonia and hypoxemia in young infants with diarrhea. PLoS One 6: e25817.

26. Magzoub MA, Bilal NE, Bilal JA, Osman OF (2014) Rotavirus infection among Sudanese children younger than 5 years of age: a cross sectional hospital-based study. Pan Afr Med J 16: 88

27. John J, Sarkar R, Muliyil J, Bhandari N, Bhan MK, et al. (2014) Rotavirus gastroenteritis in India, 2011-2013: revised estimates of disease burden and potential impact of vaccines. Vaccine 32: A5-A9.

28. Imade PE, Eghafona NO (2015) Viral agents of diarrhea in young children in two primary health centers in Edo state, Nigeria. Int J Microbiol 2015: 685821.

29. Mookerjee S, Batabyal P, Sarkar MH, Palit A (2015) Seasonal Prevalence of Enteropathogenic Vibrio and Their Phages in the Riverine Estuarine Ecosystem of South Bengal. PLoS One 10: e0137338.

30. Lakshminarayanan S, Jayalakshmy R (2015) Diarrheal diseases among children in India: Current scenario and future perspectives. J Nat Sci Biol Med 6: 24-28.

31. Sousa CPd (2008) The impact of food manufacturing practices on food borne diseases. Braz Arch of biol Technol 51: 615-623.

32. Agustina R, Sari TP, Satroamidjojo S, Bovee-Oudenhoven IM, Feskens EJ, et al. (2013) Association of food-hygiene practices and diarrhea prevalence among Indonesian young children from low socioeconomic urban areas. BMC public health 13: 977.

33. Paz MGAd, Almeida MFd, Günther WMR (2012) Prevalence of diarrhea in children and sanitation and housing conditions in periurban areas of Guarulhos, SP. Rev Bras Epidemiol 15: 188-197.

34. Dutta S, Guin S, Ghosh S, Pazhani GP, Rajendran K, et al. (2013) Trends in the prevalence of diarrheagenic Escherichia coli among hospitalized diarrheal patients in Kolkata, India. PLoS One 8: e56068.

35. Shah M, Kathiiko C, Wada A, Odoyo E, Bundi M, et al. (2016) Prevalence, seasonal variation, and antibiotic resistance pattern of enteric bacterial pathogens among hospitalized diarrheic children in suburban regions of central Kenya. Trop Med Health 29: 44-39.

36. Qadri F, Svennerholm AM, Faruque A, Sack RB (2005) Enterotoxigenic Escherichia coli in developing countries: epidemiology, microbiology, clinical features, treatment, and prevention. Clin Microbiol Rev 18: 465-483.

37. Paredes-Paredes M, Okhuysen PC, Flores J, Mohamed JA, Padda RS, et al. (2011) Seasonality of diarrheagenic Escherichia coli pathotypes in the US students acquiring diarrhea in Mexico. J travel med 18: 121-125.

38. Forster J, Guarino A, Parez N, Moraga F, Román E, et al. (2009) Hospitalbased surveillance to estimate the burden of rotavirus gastroenteritis among European children younger than 5 years of age. Pediatrics 123: e393-e400.

39. Zhang Y, Zhao Y, Ding K, Wang X, Chen X, et al. (2014) Analysis of bacterial pathogens causing acute diarrhea on the basis of sentinel surveillance in Shanghai, China, 2006-2011. Jpn J Infect Dis 67: 264-268.

40. Tobias J, Kassem E, Rubinstein U, Bialik A, Vutukuru SR, et al. (2015) Involvement of main diarrheagenic Escherichia coli, with emphasis on enteroaggregative E. coli, in severe non-epidemic pediatric diarrhea in a high-income country. BMC Infect Dis 15: 79.

41. Shah M, Odoyo E, Wandera E, Kathiiko C, Bundi M, et al. (2017) Burden of Rotavirus and Enteric Bacterial Pathogens among Children under 5 Years of Age Hospitalized with Diarrhea in Suburban and Rural Areas in Kenya. Jpn J Infect Dis 70: 442-447.

42. Thaver D, Zaidi AK, Critchley J, Azmatullah A, Madni SA, et al. (2009) A comparison of fluoroquinolones versus other antibiotics for treating enteric fever: meta-analysis. BMJ 338: b1865.

43. Banerjee I, Ramani S, Primrose B, Iturriza-Gomara M, Gray JJ, et al (2007) Modification of rotavirus multiplex RT-PCR for the detection of G12 strains based on characterization of emerging G12 rotavirus strains from South India. J Med Virol 79: 1413-1421.

44. Gentsch J, Glass R, Woods P, Gouvea V, Gorziglia M, et al. (1992) Identification of group A rotavirus gene 4 types by polymerase chain reaction. J Clin Microbiol 30: 1365-1373.

45. Gouvea V, Glass RI, Woods P, Taniguchi K, Clark HF, et al. (1990) Polymerase chain reaction amplification and typing of rotavirus nucleic acid from stool specimens. J Clin Microbiol 28: 276-282.

46. Iturriza-Gomara M, Auchterlonie IA, Zaw W, Molyneaux P, Desselberger $\mathrm{U}$, et al. (2002) Rotavirus gastroenteritis and central nervous system (CNS) infection: characterization of the VP7 and VP4 genes of rotavirus strains isolated from paired fecal and cerebrospinal fluid samples from a child with CNS disease. J Clin Microbiol 40: 4797-4799.

47. Iturriza-Gómara M, Kang G, Gray J (2004) Rotavirus genotyping: keeping up with an evolving population of human rotaviruses. J Clin Virol 31: 259-265. 